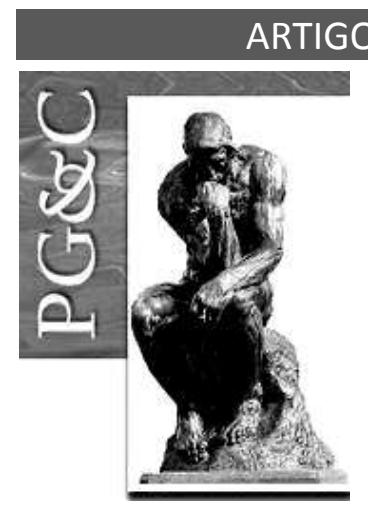

\title{
ANÁLISE DO SISTEMA DE CURRÍCULO LATTES SEGUNDO O MODELO CESM: PERSPECTIVAS PARA UM SISTEMA DE INFORMAÇÃO PARA A E-SCIENCE
}

\author{
Leonardo Lima Günther \\ Mestre em Ciência da Informação pela Universidade Federal de Santa \\ Catarina, Brasil. \\ E-mail: lg@riseup.net

\section{Roberto Carlos dos Santos Pacheco} \\ Doutor em Engenharia de Produção pela Universidade Federal de Santa \\ Catarina, Brasil. Professor da Universidade Federal de Santa Catarina, \\ Brasil. \\ E-mail: rpacheco@egc.ufsc.br \\ Gregório Varvakis \\ Doutor em Manufacturing Engineering pela Loughborough University, \\ Inglaterra. Professor da Universidade Federal de Santa Catarina, Brasil. \\ E-mail: g.varvakis@ufsc.br \\ Vinícius Medina Kern \\ Doutor em Engenharia de Produção pela Universidade Federal de Santa \\ Catarina, Brasil. Professor da Universidade Federal de Santa Catarina, \\ Brasil. \\ E-mail: v.m.kern@ufsc.br
}

\begin{abstract}
Resumo
A emergente e-science, com seu uso intensivo de dados e computação, é uma oportunidade para o Sistema de Currículo Lattes, que excede seis milhões de currículos aos 20 anos de existência. Para potencializar a oportunidade, é preciso conhecer e mobilizar os atores e fatores humanos e tecnológicos envolvidos, bem como seus vínculos. Nesse sentido, o objetivo deste artigo é descrever o Sistema de Currículo Lattes segundo o modelo de sistema composição-ambiente-estrutura-mecanismo ou CESM, de Mario Bunge, que explicita esses atores, fatores e vínculos. Os procedimentos incluem os dois primeiros passos das regras gerais da pesquisa sistemista bungeana: colocar os fatos sociais em seu contexto mais amplo (ou sistema) e dividir o sistema em sua composição, ambiente e estrutura. As fontes de informação para embasar a abstração do modelo são textos da literatura científica sobre a Plataforma e o Sistema de Currículo Lattes, bem como artigos que citam currículos Lattes como fonte de informação e documentos da Plataforma Lattes na Web. O modelo resultante é apresentado sumariamente em forma gráfica e descrito em forma textual. Discute-se a potencialidade de uso do modelo produzido no Plano de Modernização da Plataforma Lattes. Nas conclusões, apresentam-se as potencialidades da abordagem utilizada e brevemente aspectos sobre o mecanismo de controle social, que, como o estudo de outros mecanismos do sistema, é indicação para trabalhos futuros.
\end{abstract}

Palavras-chave: E-science. Plataforma Lattes. Modelo de sistema CESM. Sistemismo. Sistemas de informação. 


\title{
ANALYSIS OF THE LATTES CURRICULUM SYSTEM ACCORDING TO THE CESM MODEL: PERSPECTIVES FOR AN INFORMATION SYSTEM FOR E-SCIENCE
}

\begin{abstract}
The emerging e-science, with its intensive use of data and computing, is an opportunity for the Lattes Curriculum System, which exceeds six million curricula at 20 years of existence. Seizing the opportunity requires knowledge and mobilization of the actors and human and technological factors involved, as well as their bonds. In that sense, the objective of this article is to describe the Lattes Curriculum System according to the composition-environment-structure-mechanism system metamodel (or CESM, by Mario Bunge) that accounts for those actors, factors, and bonds. The procedures include the first two of the general methodological rules of Bunge's systemic research: placing social facts in their broader context (or system) and dividing the system into its composition, environment, and structure. Information sources for model abstraction include texts from the scientific literature on the Lattes Platform and Curriculum System, as well as articles that cite Lattes curricula as information sources, and official web pages on the Lattes Platform. The resulting model is presented in graphic and in textual form. We discuss the potential use of the model in informing the modernization plan of the Lattes Platform. We conclude by drawing on those potentialities and outlining aspects of the social control mechanism, which, as the study of other mechanisms of this system, is an indication for future work.
\end{abstract}

Keywords: E-science. Lattes platform. CESM system model. Systemism. Information systems.

\section{INTRODUÇÃO}

O Sistema de Currículo Lattes ( $\mathrm{SCL}$ ) é um dos sistemas de informação integrantes da Plataforma Lattes (PL), que conta também com o Diretório de Grupos de Pesquisa (DGP) e o Diretório de Instituições (DI). A PL iniciou suas atividades em 1999, com o lançamento do SCL pelo Conselho Nacional de Desenvolvimento Científico e Tecnológico (CNPq).

O CNPq é uma agência do Ministério de Ciência, Tecnologia, Inovações e Comunicações (MCTIC), criado em 1951, no último mandato do presidente Getúlio Vargas. Um aspecto interessante é que o CNPq, por lei, é subordinado diretamente à Presidência da República, o que sinaliza para a importância da agência dentro de uma concepção de Estado que emergiu depois da segunda guerra mundial, que tem na ciência um dos seus pilares.

Em 2019, a PL completou 20 anos, com mais de 6 milhões de currículos de indivíduos. Esse grande volume é uma das características da e-Science. Além disso, surge também a necessidade de tratar dados brutos, ou seja, de transformar informação em conhecimento usando, por exemplo, técnicas de mineração de dados. Hey e Trefethen (2003) afirmam que o termo e-Science é usado para representar as colaborações cada vez mais globais - de pessoas e de recursos compartilhados - que serão necessários para resolver os novos problemas da ciência e da engenharia.

A PL já cumpre um papel colaborativo, mas ainda encontra limites. Por isso, em dezembro de 2018, foi lançado um Plano de Modernização da PL em parceria do CNPq com várias instituições. O Plano de Modernização envolve repensar o posicionamento estratégico da Plataforma, facilitar o uso das informações e aprimorar as tecnologias de suporte, inclusive a infraestrutura (CNPq, 2018a).

O crescimento da base curricular é um dos indicativos da relevância em estudar o SCL como sistema de informação. Além disso, a PL e seus sistemas de informação já foram objeto de outros estudos publicados (KERN, 2010, 2011, PACHECO; KERN, 2001, PACHECO; KERN; STEIL, 2007). Contudo, ainda não foram desenvolvidas descrições com base empírica deste sistema com a abordagem sistemista (BUNGE, 1997; 2012b) que propomos, ou seja, existem apenas modelos ad hoc (e.g., Kern (2011)) do SCL como sistema. Sendo assim, buscaremos

Perspectivas em Gestão \& Conhecimento, João Pessoa, v. 10, n. 1, p. 107-130, jan./abr. 2020. 
responder a pergunta problema: O que é o sistema de informação Currículo Lattes? Quais são os elementos envolvidos e como eles se relacionam?

Para resolver esta problemática, descrevemos o SCL utilizando a abordagem sistemista de Bunge, definindo seus elementos componentes, do entorno e os seus vínculos (ligações) que estabelecem a estrutura do sistema. As próximas seções tratam de apresentar e contextualizar o $\mathrm{SCL}$, expor os fundamentos e procedimentos metodológicos e os resultados da pesquisa e sua discussão, concluindo com considerações finais.

\section{SISTEMA DE CURRÍCULO LATTES}

A abordagem bungeana a ser descrita na próxima seção (BUNGE, 1997, 2012b) prescreve que se inicie uma investigação por colocar cada fato social em seu contexto mais amplo ou sistema. O sistema de interesse é o $\mathrm{SCL}$, por sua vez inserido em um sistema mais amplo, a PL. Segundo o CNPq (2018b) "a Plataforma Lattes representa a experiência do CNPq na integração de bases de dados de Currículos, de Grupos de pesquisa e de Instituições em um único Sistema de Informações". Algo que deve ser ponderado é o fato de muitas pessoas confundirem o SCL com a PL. Mas ela, na verdade, inclui um conjunto de sistemas, base de dados, portais e instrumentos ligados à infraestrutura em Tecnologia da Informação. "O Sistema de Currículos é o instrumento de captura e atualização específico da unidade currículo" (PACHECO, 2003, p. 3).

Quanto aos sistemas de informação, é necessário fazer referência ao que disse Kern (2017), isto é, que há reconhecimento do caráter sociotécnico dos sistemas de informação na comunidade acadêmica. Contudo, segue a carência de teorização mais detalhada que aponte os elementos que o compõem e suas relações, considerando os aspectos sociais, não apenas os tecnológicos, ou seja, adotando uma concepção sociotecnológica que enfatiza o caráter misto dos sistemas de informação, compostos por pessoas e agentes tecnológicos em colaboração dinâmica. Para melhor compreender essa situação, é oportuno citar algumas definições encontradas na literatura. Para Laudon \& Laudon (1999, p. 4) sistema de informação pode ser definido como

[...] um conjunto de componentes inter-relacionados trabalhando juntos para coletar, recuperar, processar, armazenar e distribuir informação com a finalidade de facilitar o planejamento, o controle, a coordenação, a análise e o processo decisório em empresas e outras organizações.

Rezende (2002, p. 84) corrobora:

Os sistemas de informação são o conjunto de partes (quaisquer) que gerem informações, ou, também, o conjunto de software, hardware, recursos humanos e respectivos procedimentos que antecedem e sucedem o software. Têm como maior objetivo o apoio nos processos de tomada de decisões na empresa, e seu foco está direcionado ao principal negócio empresarial.

Portanto, sistema de informação não é software, mas o inclui. Sistemas de informação são compostos por seres humanos e artefatos que processam informação para auxiliar uma organização, ou várias, como é o caso do SCL. Estes sistemas estão em distintos níveis, uns compondo outros. A PL, por exemplo, tem vários subsistemas, como SCL, DGP e DI.

Ainda quanto ao contexto do $\mathrm{SCL}$, também está inserido em outros macrossistemas: $\mathrm{o}$ Sistema Nacional de Inovação (SNI) e o Sistema Nacional de Pós-Graduação (SNPG) (KERN,

Perspectivas em Gestão \& Conhecimento, João Pessoa, v. 10, n. 1, p. 107-130, jan./abr. 2020. 
2010, 2011). Evidência dessa inserção é o fato de a base curricular da PL ser usada no Portal Inovação, que tem nos currículos uma de suas fontes de informação, como ilustra a Figura 1.

Figura 1 - Número de atores no Portal Inovação, incluindo currículos Lattes

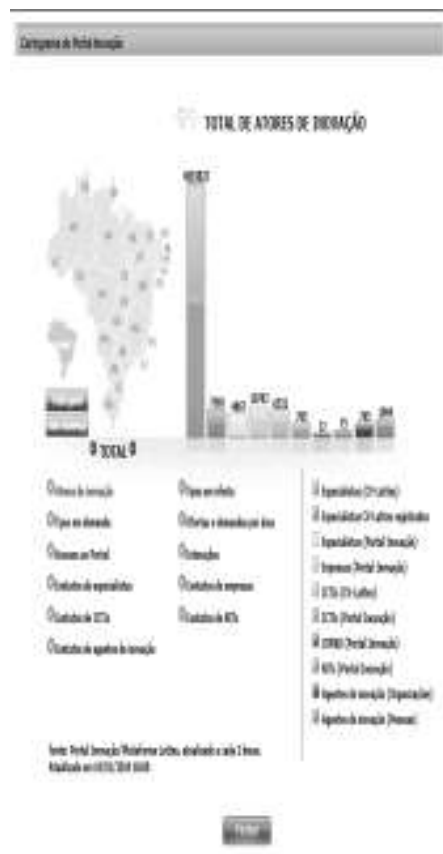

Fonte: Portal Inovação (2018), 16/01/2019

A Figura 2 dá evidência da inserção do SCL no SNI e no SNPG. No canto inferior direito, temos o CNPq e a CAPES como integrantes deste sistema.

Figura 2 - Mapa do sistema nacional de inovação brasileiro

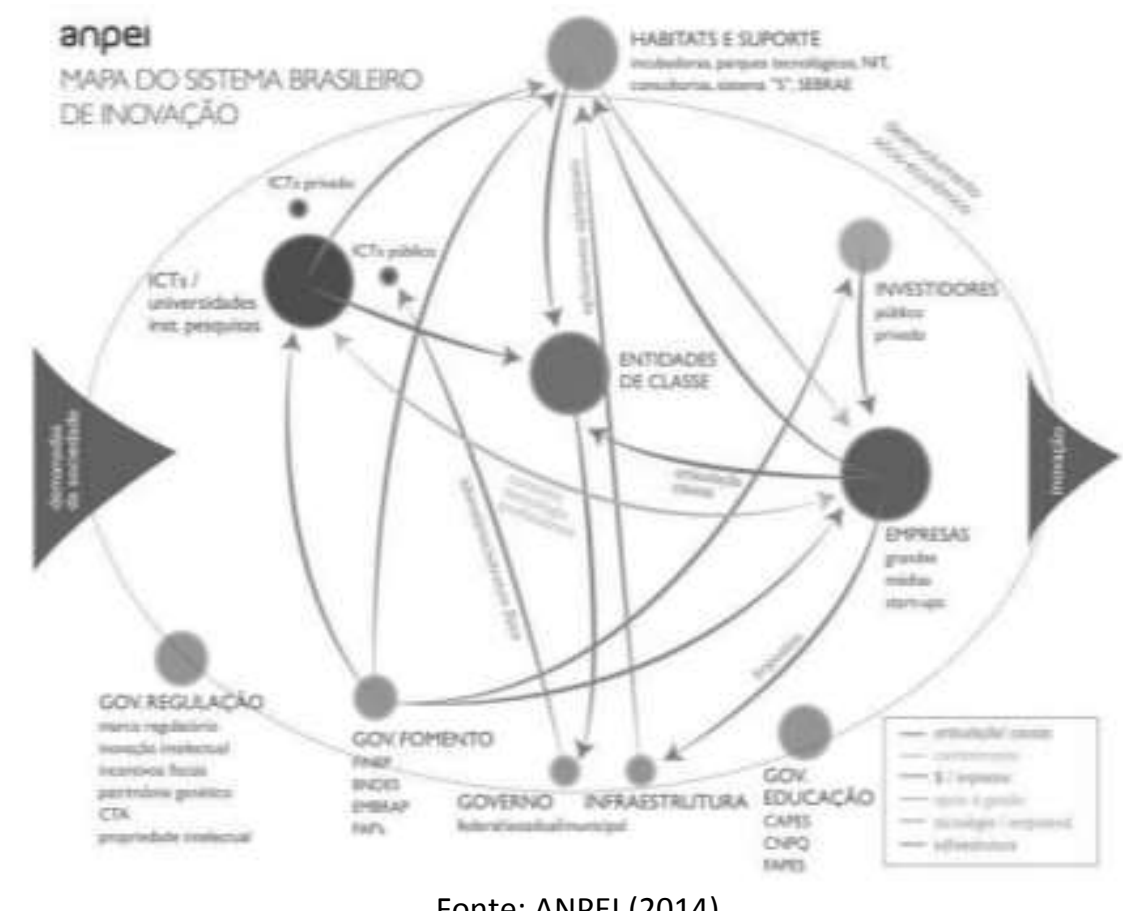

Fonte: ANPEI (2014) 
É de conhecimento público que os programas de pós-graduação brasileiros fazem uso dos currículos Lattes para intermediar seus processos burocráticos. Ele é um canal de fluxo de informação que viabiliza relações sociais, uma vez que organiza a burocracia, padroniza a informação e fomenta uma rede colaborativa científica que usa suas informações de maneira operacional e estratégica. O SNPG é desenvolvido a partir dos Planos Nacionais de PósGraduação (PNPG), que buscam ampliar e qualificar os programas de pós-graduação no país. É articulado pela CAPES e tem no Portal SINAES o seu sistema de informação. O plano está atualmente em sua sexta edição (BARRETO; DOMINGUES, 2012).

Além desses macrossistemas, o SCL e a PL induziram a gênese da Rede SCienTI (PACHECO; KERN, 2003), uma reunião das comunidades científicas da América Latina, mais Portugal, articuladas em uma rede que inclui a internacionalização da Plataforma Lattes. 0 projeto EuroCRIS é uma experiência que guarda semelhanças com a Rede ScienTI. É uma associação europeia que promove cooperação e compartilhamento de conhecimento por meio da interoperabilidade de dados e sistemas, usando um formato-padrão para informação de pesquisa.

\section{FUNDAMENTOS E PROCEDIMENTOS METODOLÓGICOS}

Nesta seção apresentamos os fundamentos do sistemismo, bem como os procedimentos de coleta de dados e posterior processo de análise, dividido em algumas etapas. É uma pesquisa descritiva em que o SCL é descrito segundo o modelo CESM de Bunge (1997, 2012b). Na tipologia quádrupla de Creswell (2008), é uma pesquisa pós-positivista.

Evitamos a dualidade equívoca "qualitativa e/ou quantitativa", que sugere quantidades e/ou qualidades mas, em realidade, diz respeito aos fundamentos realistas ("quantitativa") ou subjetivistas ("qualitativa"), conforme o mesmo Creswell (2008). A base teórico-metodológica, o sistemismo de Bunge $(1997,2012 b)$, é típica da pesquisa dita "quantitativa" embora, aqui, não tratemos de quantidades.

A principal técnica é a abstração, que, embora trate de "qualidades", difere da interpretação típica da pesquisa qualitativa, pois não trata de subjetividades. Segundo Bunge (2005, p. 114), a abstração é uma "desinterpretação", pois é empiricamente contrastável. A pesquisa foi realizada entre o primeiro semestre de 2016 e o segundo semestre de 2018 .

\subsection{Sistemismo bungeano}

Falar do sistemismo bungeano requer compreender como Bunge define sistema. No livro Emergência e Convergência, "sistema" é [...] um objeto complexo cujos componentes se encontram unidos por fortes vínculos - lógicos, físicos, biológicos ou sociais - e que possuem propriedades globais (emergentes) das quais seus componentes carecem" (BUNGE, 2012b, p.361).

No livro Caçando a Realidade, Bunge explica com mais detalhes:

Um sistema é um objeto complexo cujas partes ou componentes são mantidas juntas por liames de alguma espécie. Esses liames são lógicos, no caso de um sistema conceitual, como uma teoria, e são materiais, no caso de um sistema concreto, como um átomo, uma célula, um sistema imune, uma família ou um hospital. A coleção de todas as relações desse tipo entre os constituintes de um sistema é sua estrutura (ou organização, ou arquitetura). Esse conceito de estrutura é tomado de empréstimo da matemática (BUNGE, 2010, p.186).

Perspectivas em Gestão \& Conhecimento, João Pessoa, v. 10, n. 1, p. 107-130, jan./abr. 2020. 
Dessa forma, ele postula que tudo no universo é um sistema ou parte de um. O sistemismo, como Bunge (2010, 2012b) nomeou a abordagem, é uma ontologia materialista emergentista. Ou seja, para ele, a realidade pode ser organizada em sistemas de diversos níveis e esses sistemas fazem emergir na realidade qualidades que suas partes sozinhas não possuem. O filósofo da ciência, recentemente falecido, desenvolveu essa abordagem desde meados do Século XX. Ela adota como ontologia o sistemismo e, como parceiro epistemológico, o realismo científico. Postula que metodologicamente deve realizar análise e síntese com o objetivo de contribuir para uma melhor compreensão do sistema uma vez que fornece diferentes ferramentas para explicar o objeto (BUNGE, 2012b).

A análise consiste na decomposição de um todo em seus componentes e as relações destes, ou seja, o antônimo de síntese. A análise pode ser conceitual, empírica ou ambas. A análise empírica consiste em separar os componentes de um todo concreto. A análise deve fazer uso da abstração, que é uma porta para a generalização, que significa procurar diretrizes sob os detalhes (BUNGE, 2005).

Nesta pesquisa, procuramos propriedades em comum nos elementos. Por outro lado, a síntese consiste na montagem ou combinação, de maneira natural ou artificial, de objetos de diferentes tipos. Exemplos de sínteses são as classificações, as teorias, os desenhos de experimentos e os planos (BUNGE, 2005).

Entender esses aspectos permite compreender a primeira etapa da abordagem sistemista (BUNGE, 1997), ou seja, colocar o fato social no contexto mais amplo, de interesse, como mencionamos na seção anterior. Para tanto, nos referenciamos na literatura que aponta como macrossistemas do nosso sistema de estudo o SNI e o SNPG. Contudo, cabe frisar, poderiam ser escolhidos outros macrossistemas como referência.

A segunda etapa da abordagem sistemista é realizar a redução do sistema a seus componentes, itens do ambiente e ligações componente-componente e componenteestrutura. Para isso se escolhe um nível de modelagem, onde serão indicados os componentes, os elementos de entorno e as relações de um sistema, isto é, os vínculos existentes entre componentes do sistema e destes com os elementos de entorno. Essas são as três primeiras coordenadas estabelecidas por Bunge (1999, 2010, 2012a, 2012b) para iniciar a construção do modelo CESM (do inglês composition, environment, structure, and mechanism). Tal descrição busca explicitar o que é esse sistema e assim poderemos ter melhores condições, no futuro, de conjeturar seus mecanismos e dizer como o sistema funciona.

Uma vez delineado o conceito de sistema, bem como breves comentários sobre a produção de um modelo, podemos partir para um entendimento mais específico de sua aplicação: a abordagem (enfoque) sistemista. A respeito disso, Bunge (1999, p. 370) alerta:

Recordemos que um enfoque, ou maneira de mirar as coisas e manejá-las, está composto de um corpo de conhecimentos existentes junto com um conjunto de problemas (problemática), um conjunto de objetivos e um conjunto de métodos (metódica) para enfrentar tais problemas. Já que o enfoque sistemático é hipergeral, os únicos elementos que se podem apresentar em seu conhecimento existente são certas hipóteses filosóficas. Estas consistem essencialmente em um princípio ontológico e sua contraparte epistemológica. O primeiro é o princípio de que toda coisa concreta é ou bem um sistema ou um componente de um. Seu companheiro epistemológico é a norma de que todo o sistema deve estudar-se em seu próprio nível, assim como decompor-se em seus componentes interatuantes (grifo do autor).

Para tanto, é necessário ter em mente que essa abordagem tem como premissa metodológica o desenvolvimento de modelos ad hoc, qualitativos, quantitativos, cinemáticos,

Perspectivas em Gestão \& Conhecimento, João Pessoa, v. 10, n. 1, p. 107-130, jan./abr. 2020. 
dinâmicos, dentre outros (BUNGE, 2012a). Tal autor explica que o mais simples modelo (também chamado de esboço ou croqui) de um sistema concreto $S$, em um dado instante, possui as quatro coordenadas: $\mu(s)=\langle C(s), E(s), S(s), M(s)>$.

$C(s)$ é a coleção de todas as partes de $S$. $E(s)$ é a coleção de elementos não pertencentes a $S$, mas que atuam sobre os componentes de $S$ e vice-versa (sobre todos ou apenas sobre alguns). $S(s)$ é a coleção de relações - vínculos ou laços - entre os componentes de $S$ e entre estes e os elementos do entorno $E(s)$. Por fim, $M(s)$ é a coleção de processos que fazem com que $S$ se comporte como sistema, com propriedades emergentes, que os componentes não têm.

Contudo, Bunge (2012b) assevera que um modelo CESM pleno é, na prática, impossível de manejar. Isso ocorre porque seria necessário conhecer todos os componentes, todos os elementos do entorno e todos os vínculos e processos de seu funcionamento. Portanto, é necessário escolher certo nível de análise, limitando o escopo. Posteriormente, faz-se uma síntese representada por um modelo de caixa-preta (apenas entradas e saídas), cinza (descritiva de partes e ligações, mas sem revelar mecanismo) ou translúcida (BUNGE, 2013). No caso da nossa pesquisa, o que teremos como resultado é uma caixa cinzenta, pois conjeturar os mecanismos e construir uma caixa translúcida não é nosso objetivo.

Contudo, primeiramente, como orienta Kern (2011), é necessário listar as sete regras metodológicas gerais para a abordagem sistemista de problema. Estas servirão de roteiro para um enfoque sistemista. Encontramos essas regras em artigo de Bunge (1997, p. 458):

1) Colocar todo fato social em seu contexto mais amplo (ou sistema);

2) Dividir cada sistema em sua composição, ambiente e estrutura;

3) Distinguir os vários níveis de sistema e exibir suas relações;

4) Procurar os mecanismos que mantêm um sistema funcionando ou levam à sua decadência ou crescimento;

5) Ter razoável certeza de que o mecanismo proposto é compatível com as leis e as normas relevantes e conhecidas e, se possível, verificar a hipótese ou teoria mecanísmica manipulando experimentalmente as variáveis referidas;

6) Mantidas as demais condições, preferir hipóteses, teorias e explicações mecanísmicas (dinâmicas) às fenomenológicas (cinemáticas) e, em seu turno, preferir essas descrições cinemáticas aos modelos de equilíbrio e às descrições de dados;

7) Em caso do mau funcionamento do sistema, examinar todas as quatro fontes possíveis - composição, ambiente, estrutura e mecanismo - e tentar reparar o sistema alterando algumas ou todas as fontes.

Apresentadas as etapas, é necessário informar que, neste artigo, concentramo-nos somente na primeira e segunda etapas acima - ou seja, descrevemos a composição, ambiente e estrutura do $\mathrm{SCL}$, aspectos detectáveis, mas não o mecanismo, que precisa ser conjeturado e testado. Essas duas etapas são necessárias para realizar a descrição do sistema e para poder avançar para as demais. Bunge (1979, p. 8-9) reconhece que é difícil modelar um sistema concreto, "particularmente se está fortemente acoplado a outros sistemas", como é o caso do $\mathrm{SCL}$, e que modelar é um problema científico, não ontológico.

A Etapa Um "trata da descrição dos aspectos usualmente observáveis (mas não necessariamente palpáveis) de um sistema" (KERN, 2011, p. 2700). Passar por essas etapas proporciona poder heurístico e sistematizador para o estudo, desde que tomadas junto à procura de ligações e junto ao método científico tradicional (BUNGE, 1997).

Por fim, a problemática do enfoque sistêmico envolve todos os problemas cognitivos ou práticos em qualquer classe de sistemas. Além disso, os seus objetivos são os mesmos da

Perspectivas em Gestão \& Conhecimento, João Pessoa, v. 10, n. 1, p. 107-130, jan./abr. 2020. 
ciência e da tecnologia, ou seja, descrever, entender, predizer e controlar. No que tange à metódica, o enfoque sistêmico inclui tanto a análise quanto a síntese, bem como a generalização e a sistematização, o modelo matemático e a comprovação empírica, em laboratório ou no campo (BUNGE 1999). Em resumo, utilizamos o método científico aliado à abordagem sistemista aplicada à Ciência da Informação, como proposto por Kern $(2010,2011)$, Kern et al. (2016), além das orientações de Bunge (1966, 1999, 2005, 2010, 2012a, 2012b, 2013) para a realização de pesquisas científicas.

Neste trabalho o escopo é levantar dados para dar base empírica ao modelo ad hoc utilizado como ponto de partida (KERN, 2010, 2011) para, então, qualificá-lo e complexificá-lo (BUNGE, 2013). Kern (2010) apresenta um modelo CESM ad hoc da PL sociotecnológica, embora o escopo seja limitado ao SCL. Por isso, foi possível utilizá-lo como ponto de partida. $O$ segundo artigo, de 2011, apresenta um roteiro para estudar sistemas de informação utilizando a abordagem sistemista de Bunge.

\subsection{Coleta e análise de dados}

Para realizar essa descrição, selecionamos alguns materiais, dentro de uma metódica que segundo Bunge (1999) permite dar melhores elementos para inferir as estruturas de um sistema social. Na citação abaixo, entre chaves, colocamos cada grupo de materiais selecionados - conjuntos de dados empíricos e da literatura - para atender à técnica recomendada, em especial, para poder inferir as estruturas do sistema e para conseguir compor o modelo CES. Diz ele:

[O cientista social] deve também descobrir a forma em que são "percebidas" [as estruturas/vínculos] pelos membros dos sistemas que estuda. A razão é que as crenças, sejam verdadeiras ou falsas, influem nas ações. Por exemplo, uma pessoa atuará de uma forma se crê que uma estrutura é imutável e de outra forma diferente se crê que pode ser alterada. Para cada terna sociedade-ator-sociólogo, temos que lidar com quatro estruturas diferentes: a) a estrutura objetiva \{buscamos no site da PL\} e b) a representação subjetiva dessa realidade imaginada pelo agente \{buscamos nos artigos dos usuários - aqueles que utilizaram o Currículo Lattes como fonte de informação para suas pesquisas\} e os modelos teóricos da primeira \{buscamos nos artigos dos desenvolvedores da PL e da segunda \{buscamos nos artigos de Kern $(\mathbf{2 0 1 0}, \mathbf{2 0 1 1})\}$ que o cientista social constrói. Esta divisão quádrupla engloba tanto o aspecto objetivo quanto o subjetivo" (BUNGE, 1999, p. 384, tradução nossa) (os trechos entre chaves são apontamentos sobre como verificamos os vínculos).

Explicamos: o primeiro material que utilizamos como fonte foi o sítio na Web da PL em especial o SCL. Lá como em todos os outros materiais, buscamos extrair (após identificação ontológica) descritores do SCL. O segundo conjunto de materiais utilizados foram artigos, nos quais, os autores utilizam o Currículo Lattes como fonte de informação. A coleta desses artigos ocorreu nas bases Web of Science, Scopus e Base de Dados em Ciência da Informação (BRAPCI). Tais artigos apresentam uma percepção dos usuários (pesquisadores) do sistema, portanto uma visão subjetiva, pois apenas manifestam a usabilidade do artefato, embora estejam envolvidos em outro escopo de pesquisa. Justificamos o uso da BRAPCI por ser uma base de dados específica do campo científico da ciência da informação. As demais justificamos pela qualidade no processo seletivo dos artigos que as compõem. Os artigos coletados constam nos Quadros 1 (BRAPCI), 2 (Scopus ) e 3 (Web of Science).

Perspectivas em Gestão \& Conhecimento, João Pessoa, v. 10, n. 1, p. 107-130, jan./abr. 2020. 
Quadro 1 - Artigos coletados na BRAPCI

\begin{tabular}{|c|c|c|}
\hline Autores & Título & Periódico \\
\hline $\begin{array}{l}\text { GOMES; } \\
\text { MOITA. }\end{array}$ & $\begin{array}{l}\text { Uma análise dos principais tópicos investigados pelos } \\
\text { pesquisadores doutores brasileiros. }\end{array}$ & $\begin{array}{l}\text { Em Questão, v.24, } \\
\text { n.2, p.55-82, 2018. }\end{array}$ \\
\hline PERUCCHI; MUELLER. & $\begin{array}{l}\text { Produção dos professores dos Institutos Federais de } \\
\text { Educação, Ciência e Tecnologia no currículo da } \\
\text { Plataforma Lattes. }\end{array}$ & $\begin{array}{l}\text { Informação \& } \\
\text { Informação, v.22, n.1, } \\
\text { p.111-128, 2017. }\end{array}$ \\
\hline $\begin{array}{lr}\text { MOREIRA; } & \text { ALVES; } \\
\text { SILVA; } & \text { FREITAS; } \\
\text { LAZZARIN. } & \end{array}$ & $\begin{array}{l}\text { Ranking da produção científica do Programa de Pós- } \\
\text { Graduação em Ciência da Informação da Universidade } \\
\text { de São Paulo. }\end{array}$ & $\begin{array}{l}\text { Folha de Rosto, v.3, } \\
\text { n. esp., p.53-60, } \\
2017 .\end{array}$ \\
\hline $\begin{array}{l}\text { ANDRÉ; } \\
\text { LUCAS. }\end{array}$ & $\begin{array}{l}\text { Perfil do corpo docente do Programa de Pós-Graduação } \\
\text { em Gestão da Informação da Universidade do Estado de } \\
\text { Santa Catarina. }\end{array}$ & $\begin{array}{l}\text { Revista ACB, v.22, } \\
\text { n.3, p.514-533, } 2017 .\end{array}$ \\
\hline DIAS; MOITA; DIAS. & $\begin{array}{l}\text { Adoção da Plataforma Lattes como fonte de dados para } \\
\text { caracterização de redes científicas. }\end{array}$ & $\begin{array}{l}\text { Encontros Bibli, v.21, } \\
\text { n.47, p.16-26, } 2016 .\end{array}$ \\
\hline $\begin{array}{l}\text { DIGIAMPIETRI; } \\
\text { MUGNAINI; MENA- } \\
\text { CHALCO; DELGADO; } \\
\text { ALCÁZAR. }\end{array}$ & $\begin{array}{l}\text { Análise macro das últimas atualizações dos Currículos } \\
\text { Lattes. }\end{array}$ & $\begin{array}{l}\text { Em Questão, v.20, } \\
\text { n.3 - edição especial, } \\
2014 \text {. }\end{array}$ \\
\hline
\end{tabular}

Fonte: Dados da pesquisa $(2016 ; 2018)$

Quadro 2 - Artigos coletados na Scopus

\begin{tabular}{|c|c|c|}
\hline Autores & Título & Periódico ou anais \\
\hline $\begin{array}{lr}\text { VIANNA; } & \text { PIERANTONI; } \\
\text { FRANÇA; } & \text { MAGNAGO; } \\
\text { RODRIGUES; } & \text { MORICI. }\end{array}$ & $\begin{array}{l}\text { Modelos econométricos de estimativa da } \\
\text { força de trabalho: uma revisão } \\
\text { integrativa da literatura. }\end{array}$ & $\begin{array}{l}\text { Physis, v. 23, n. 3, p. 925-950, } \\
2013 .\end{array}$ \\
\hline $\begin{array}{l}\text { BRITO; QUONIAM; MENA- } \\
\text { CHALCO. }\end{array}$ & $\begin{array}{l}\text { Exploração da Plataforma Lattes por } \\
\text { assunto: proposta de metodologia. }\end{array}$ & $\begin{array}{l}\text { TransInformação, v. 28, n. 1, p. } \\
\text { 77-86, } 2016 .\end{array}$ \\
\hline $\begin{array}{l}\text { VIEIRA; WELTER; MELLO- } \\
\text { CARPES. }\end{array}$ & $\begin{array}{l}\text { Perfil dos Grupos de Pesquisa em } \\
\text { Neurofisiologia do Brasil. }\end{array}$ & $\begin{array}{l}\text { Revista Neurociências, v. 22, n. } \\
\text { 1, p.:37-44, } 2014 .\end{array}$ \\
\hline $\begin{array}{l}\text { AMARAL; BRITO; ROCHA; } \\
\text { QUONIAM; FARIA. }\end{array}$ & $\begin{array}{l}\text { Panorama da inteligência competitiva no } \\
\text { Brasil: os pesquisadores e a produção } \\
\text { científica na Plataforma Lattes. }\end{array}$ & $\begin{array}{l}\text { Perspectivas em Ciência da } \\
\text { Informação, v.21, n.4, p.97- } \\
\text { 120, } 2016 .\end{array}$ \\
\hline $\begin{array}{l}\text { ALVES; SOUZA; YANASSE; } \\
\text { SOMA. }\end{array}$ & $\begin{array}{l}\text { Mapeamento de competências } \\
\text { tecnológicas: um sistema de informação } \\
\text { para auxiliar o processo de decisão da } \\
\text { Petrobrás baseado na Plataforma Lattes. }\end{array}$ & $\begin{array}{l}\text { 10th Iberian Conference on } \\
\text { Information Systems and } \\
\text { Technologies (CISTI), p. 1-6, } \\
2015 .\end{array}$ \\
\hline AMORIN. & $\begin{array}{l}\text { Organização do currículo - Plataforma } \\
\text { Lattes. }\end{array}$ & $\begin{array}{l}\text { Pesquisa Odontológica } \\
\text { Brasileira, v. 17, supl. 1, p. 18- } \\
22,2003 .\end{array}$ \\
\hline ENGELMANN. & $\begin{array}{l}\text { Estudos no exterior e mediação de } \\
\text { modelos institucionais: o caso dos } \\
\text { juristas brasileiros. }\end{array}$ & $\begin{array}{l}\text { Revista de Sociologia e Política, } \\
\text { v. } 16 \text {, n. suplementar, p. } 145- \\
157,2008 .\end{array}$ \\
\hline $\begin{array}{l}\text { OLIVEIRA } \\
\text { HOCHMAN; } \\
\text { FERREIRA. }\end{array}$ & $\begin{array}{l}\text { Fomento à publicação científica e } \\
\text { proteção do conhecimento científico. }\end{array}$ & $\begin{array}{l}\text { Acta Cirúrgica Brasileira, v. 20, } \\
\text { p. } 35-39,2005 .\end{array}$ \\
\hline
\end{tabular}

Fonte: Dados da pesquisa $(2016 ; 2018)$ 
Quadro 3 - Artigos coletados na Web of Science

\begin{tabular}{|c|c|c|}
\hline Autores & Título & Periódico \\
\hline $\begin{array}{l}\text { ARBOIT; } \\
\text { GONZÁLEZ. }\end{array}$ & $\begin{array}{l}\text { A produção brasileira em Ciência da } \\
\text { Informação no exterior como reflexo de } \\
\text { institucionalização científica. }\end{array}$ & $\begin{array}{l}\text { Perspectivas em Ciência da } \\
\text { Informação, v.16, n.3, p.75-92, } \\
2011 .\end{array}$ \\
\hline $\begin{array}{l}\text { SINISTERRA; SPEZIALI; } \\
\text { GUIMARÃES; SILVA. }\end{array}$ & $\begin{array}{l}\text { Panorama de propriedade intelectual, } \\
\text { transferência de tecnologia e inovação da } \\
\text { química brasileira e a comparação com } \\
\text { países do BRIC. }\end{array}$ & $\begin{array}{l}\text { Química Nova, v. } 36, \text { n. 10, p. } \\
\text { 1527-1532, } 2013 .\end{array}$ \\
\hline $\begin{array}{l}\text { SANTOS; } \\
\text { KUPPENS. }\end{array}$ & $\begin{array}{l}\text { Produtividade em pesquisa CNPq: análise } \\
\text { do perfil dos pesquisadores da Química. }\end{array}$ & $\begin{array}{l}\text { Química Nova, v. 33, n. 2, p. } \\
\text { 489-495, } 2010 .\end{array}$ \\
\hline MARCELINO. & $\begin{array}{l}\text { Hospitalidade: questão de igualdade e de } \\
\text { gênero. }\end{array}$ & $\begin{array}{l}\text { Rosa dos Ventos - Turismo e } \\
\text { Hospitalidade, v. } 10 \text {, n. 2, p. } \\
\text { 285-300, 2018. }\end{array}$ \\
\hline $\begin{array}{l}\text { NORONHA; POBLACIÓN; } \\
\text { ASSIS; HYODO. }\end{array}$ & $\begin{array}{l}\text { Egressos dos programas de pós- } \\
\text { graduação em ciência da informação: por } \\
\text { onde andam os doutores? }\end{array}$ & $\begin{array}{l}\text { Perspectivas em Ciência da } \\
\text { Informação, v. 14, n. 2, p. 94- } \\
\text { 107, } 2009 .\end{array}$ \\
\hline
\end{tabular}

Fonte: Dados da pesquisa $(2016 ; 2018)$

O terceiro material é composto por um conjunto de artigos selecionados intencionalmente que abordam como tema plataformas e-gov, em especial, aquelas fomentadoras da colaboração científica: Pacheco e Kern (2001), Pacheco (2003), Balancieri et al. (2005), Pacheco, Kern e Steil (2007) e Lane (2010). Por fim, os últimos materiais são trabalhos que enfocam o sistemismo (KERN, 2010, 2011) e o meta modelo CESM de Bunge (1999, 2010, 2012a, 2012b).

Essa seleção busca atender a divisão quádrupla apresentada por Bunge (1999) para construir um modelo social: a) estrutura objetiva; b) estrutura subjetiva imaginada pelo agente; c) modelo teórico da estrutura objetiva e d) modelo teórico da estrutura subjetiva imaginada pelo agente. Na Figura 3 apresentamos um organograma das etapas da pesquisa são referenciados os apêndices da dissertação que é fonte para este artigo (GÜNTHER, 2019).

O SCL não é um sistema social e técnico tão palpável quanto um hospital hi-tech ou uma fazenda. Conseguimos perceber a sua existência diante de uma série de evidências empíricas. A análise e a síntese executadas usam dados encontrados nas evidências documentais (artigos científicos e sites). Extraímos descritores destes materiais, buscando evidências de elementos do SCL. O procedimento adotado consiste em ler a fonte, anotar parágrafos que tenham descritores que tragam evidências de componentes, itens do ambiente (entorno) e estrutura do sistema. 
Figura 3 - Organograma das etapas da pesquisa

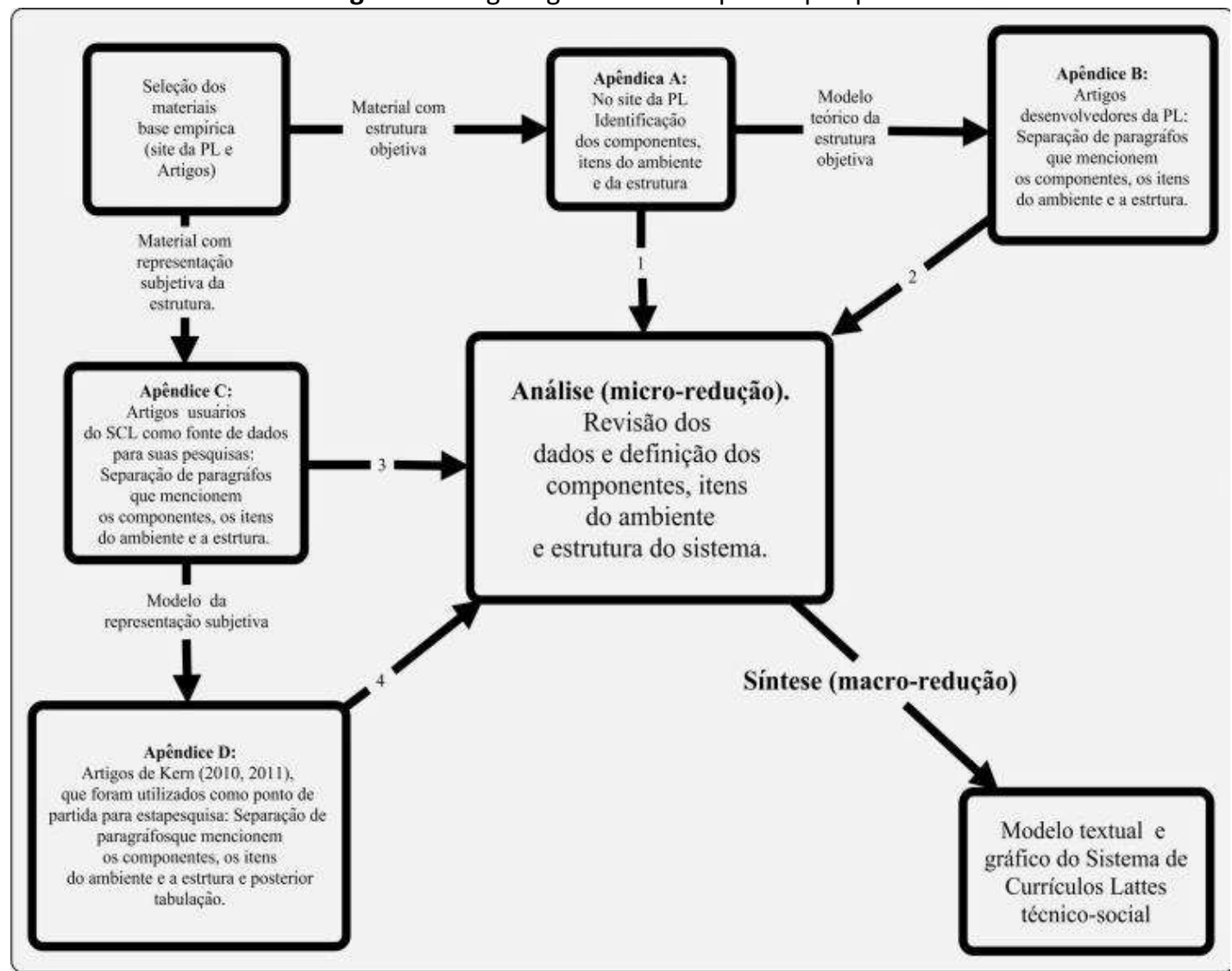

Fonte: Günther (2019)

Chamamos esse recorte de parágrafo, de "citações". Destacamos na Figura 4, no parágrafo recortado em negrito, algumas palavras (chamamos descritores) que atenderam aos critérios de recorte (ontologia). Então organizamos o instrumento desta forma: a) título do artigo; b) dados para citação do artigo e; c) três listas (componentes, entorno e estrutura), onde colocamos todos os descritores encontrados no artigo (lista geral). Esta lista geral foi utilizada como base para construção de um modelo que apresentaremos na próxima seção. 
Figura 4 - Instrumento de coleta de dados na pesquisa

PRODUC̣ÃO DOS PROFESSORES DOS INSTITUTOS FEDERAIS DE EDUCAC̣ÃO, CIENCIA E TECNOLOGIANO CURRICULO DA PLATAFORMA LATTES

\author{
ValmiraPerucchi* \\ Suzana Pinheiro Machado Mueller** \\ Inf. Inf., Londrina, v.22, n. 1, p. 111-128,jan_/abr.,2017. \\ http:www.uel.br/revistas/informacao/ \\ Componentes: profess ores, curriculo, pesquisador
}

Entorno: Instituto Nacional da Propriedade Industrial (INPI), Institutos Federais, Secretaria de Educacão Profissional e Tecnológica (SETEC), Ministério da Educação (MEC), Conselho Nacional de Desenvolvimento Cientifico e Tecnológico $\left(\mathrm{CNPq}_{\text {es }}\right.$ instituições de ensino superior,

Estrutura: artigo cientifico e a patente, depósito de patentes, Produção bibliográfica: artigo completo publicado em periódicos; capítulo de livro; livro; trabathos publicados em anais de eventos; apres entação de trabalho el palestra; partitura musical; tradução; prefácio e posfácio e outra produção bibliográfica. - Produção tícnica: assess oria e consultoria; extensão tecnológica; programa de computador sem registro; produtos; proces50s ou técnicas; trabalhos técnicos; cartas, mapas ou similares; curso de curta duração ministrado; des envolvimento de material didático ou instucional; editoração; mamutenção de obra artistica; maquete; entrevistas, mesasredondas, programas e comentários na midia; relatório de pesquisa; redes sociais, websites e blogs e outra produção técnica. - Inovação: patente; programa de computador registrado; cultivar protegida; cultivar registrada; desenho incustrial registrado; marca registrada; topografia de circuito integrado registrado; programa de computador sem registro; produtos; processos ou técnicas; projetos de pesquisa; projetos de

des envelyimento tecnológico; projetos de extensão e outros projetos.-Patentes e registros: patente; programa de computador registrado; cultivar protegida; cultivar registrada; des enho industrial registrado; marca registrada e topografia de circuito integrado registrado.

Citações:

$\mathrm{O}$ artigo científico e a patente são canais formais que têm em commm a avaliação pelos pares. $\mathrm{O}$ artig̣ é submetido a um periódico cientifico e é analisado por avaliadores, membros de seu corpo editorial ou especialis tas especialmente designados. Ao publicar um artigo em revista referendada, o autor registra formalmente sua antoria mas is 50 se refere a0s snteúdos, nãoge canal. Na maioria das revistas cientificas produzidas por editores comerciais, os direitos autorais sobre o artigo publicado são geralmente cedidos pelo autor à revista. Nas revistas de acesso aberto, essa prática vem mudando. Por outro lado, o depósito de patentes segue um caminho diferente. As patentes submetidas ao Instituto Nacional da Propriedade Industrial (INPI) são primeiramente analisadas por técnicos desse Instituto. Quando concedida a patente, ela pertence a quem a solicitou. P. 115

Fonte: Günther (2019)

Os descritores encontrados na fonte representada na Figura 4 são reunidos a outros descritores encontrados em outras fontes, para então fazer a síntese dos componentes, itens do ambiente e ligações. Os resultados são apresentados a seguir.

\title{
4 RESULTADOS
}

O SCL foi desenvolvido por uma equipe organizada em sistemas institucionais com vistas a resolver um problema: a dispersão das informações sobre a comunidade científica em diferentes currículos (MOTOYAMA, 2002). Atingido esse objetivo, emerge o problema frente a necessidade de modernização permanente da PL diante da enxurrada de dados recebidos nos últimos vinte anos. Essa é uma demanda de sistemas de informação voltados para a colaboração científica em redes. Essa modernização passa tanto pelo aspecto tecnológico, quanto sociológico. Portanto, a interação entre seres humanos, instituições, elementos tecnológicos, Tecnologia da Informação (TI), (em especial na chamada Grade ou Grid em inglês), sintetizam um sistema de informação em funcionamento na e-Science (HEY e TREFETHEN, 2003).

Contudo, para explicar como funciona determinado sistema é necessário antes saber o que é e como é esse sistema. Por isso, o trabalho de descrever o SCL utilizando o sistemismo proposto por Bunge, e seu modelo CES com base empírica caracteriza-se como contribuição

Perspectivas em Gestão \& Conhecimento, João Pessoa, v. 10, n. 1, p. 107-130, jan./abr. 2020. 
para estudos sobre o SCL e a PL. Assim, será apresentado modelo como resultado, pois este, segundo Bunge (2010), proporciona maior poder heurístico para pesquisa. A abstração precisa atender a no mínimo alguns requisitos ontológicos (nosso caso o sistemismo) quando pretende descrever determinado objeto. Assim, passamos a procurar elementos que compõem todos os sistemas de informação, que é uma espécie de sistema técnico. Este possui na sua composição seres racionais e artefatos (nosso caso, software) e no seu entorno há componentes de uma sociedade, como por exemplo, instituições ou grupos sociais (CNPq e a comunidade científica). Por fim, todo o sistema técnico tem como estrutura a produção, a manutenção e/ou a utilização de artefatos (BUNGE, 2012a).

Adotando esse raciocínio como premissa, fizemos os movimentos epistêmicos que recomenda a teoria sistemista, ou seja, a análise e a síntese, a abstração e a generalização. A seguir apresentamos o modelo síntese dos dados empíricos coletados que foram submetidos aos procedimentos metodológicos. Após o modelo gráfico sintético (Figura 5), será descrito cada componente (retângulo interno à elipse que delimita o $\mathrm{SCL}$ ), item do ambiente (retângulo externo à elipse) e a estrutura do sistema (linhas rotuladas - contínuas para a endoestrutura e pontilhadas para a exoestrutura).

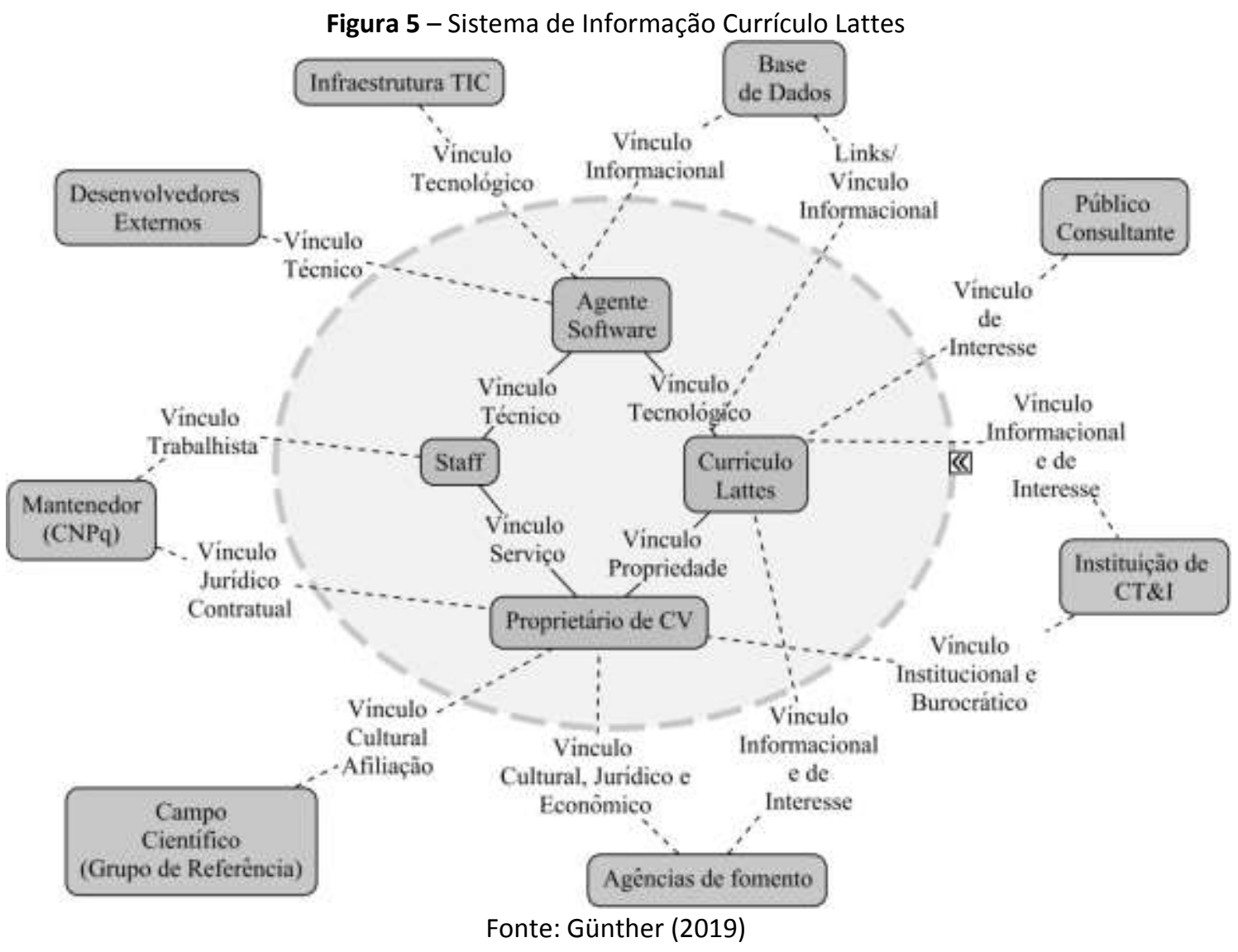

Como dito em seção anterior, os componentes do sistema de CL correspondem à sua coleção de elementos constituintes. Para extrair os dados dos materiais buscamos atender o nosso compromisso ontológico. Para tanto, buscamos encontrar descritores (dados) nos materiais que correspondam às coordenadas ontológicas pré-definidas de um sistema de informação, ou seja, identificar os componentes (humanos e artefatos), itens do ambiente e estrutura. Após, iniciamos um processo de análise, ou seja, de decomposição do sistema. Esse processo completo pode ser encontrado nas listas de elementos do sistema nos Apêndices $A$,

Perspectivas em Gestão \& Conhecimento, João Pessoa, v. 10, n. 1, p. 107-130, jan./abr. 2020. 
B, C e D da dissertação de mestrado que originou este artigo (GÜNTHER, 2019). Nesses apêndices serão encontradas as listas com os dados extraídos conforme apresentado na seção Materiais e Métodos. Como resultado, obtivemos um total de 52 descritores, muitos deles repetidos em distintos materiais. Como explicado na seção anterior, realizamos análise, revisão e validação desses componentes e percebemos algumas propriedades em comum. Isso permitiu o movimento de síntese e generalização que reduziu o conjunto de elementos a apenas quatro, como vimos na Figura 5. São eles: (1) Agente de Software; (2) Currículo Lattes; (3) Proprietário do Currículo; e (4) Staff do Mantenedor. A seguir, apresentaremos uma descrição destes quatro componentes do sistema.

Quanto à estrutura do sistema, o escopo da pesquisa é descrever as relações entre os seus componentes e destes com os itens do ambiente e vice-versa. Portanto, iniciaremos pelas relações entre os componentes do SCL. Primeiro, é importante ater-se ao que descrevemos quanto à coleção de relações existentes entre os componentes e destes com o seu ambiente. As relações apontadas são o resultado do processo de síntese e generalização. As listas completas de relações podem ser encontradas nos apêndices da dissertação que origina este artigo (GÜNTHER, 2019). A exoestrutura trata das ligações componente-ambiente e a endoestrutura, das ligações componente-componente. Ligações entre itens do ambiente estão fora do escopo de modelagem (e qualquer análise dessas ligações é atividade de modelagem de algum outro sistema, de nível mais amplo. A seguir, descrevemos cada componente, elemento de entorno e estrutura do SCL de acordo com o modelo apresentado na Figura 5.

O componente Agente de Software é formado por softwares que permitem o funcionamento da PL e, por consequência, do SCL. Nos artigos, encontramos ao menos três agentes de software: agentes ETL (extraction, transaction, and load), agentes de análise e síntese e agentes conectores. Segundo Kern (2010, p. 11), esses agentes "realizam tarefas de complexidade variável, desde o transporte de currículos entre estágios do seu armazenamento até a descoberta de conhecimento em texto ou banco de dados (KDT - knowledge discovery in text, KDD - knowledge discovery in databases)".

Nos demais materiais selecionados não foram encontradas referências sobre agentes de software. Portanto, foi possível fazer a síntese e chegar a apenas um elemento e a uma tipologia que abarca a propriedade que é comum em todos os três: o fato de serem agentes de software que realizam trabalho burocrático e analítico. Esse componente possui relação com o Staff e com o CL. Sua relação com o ambiente é com o Desenvolvedor Externo, com a Infraestrutura de tecnologia da informação e comunicação (TIC) e com a Base de Dados.

O componente Agente de Software possui relação endoestrutural com o Currículo Lattes e, assim, estabelece com ele um vínculo tecnológico, ou seja, ele opera sobre a programação do software. Por outro lado, a relação com o Staff é definida por um vínculo técnico, ou seja, o ser humano opera sobre o hardware e mobiliza o software, que por sua vez, realiza mudanças no site da PL.

O componente Currículo Lattes é o principal artefato desse sistema de informação (KERN, 2010, 2011). Os demais componentes do sistema possuem relação direta ou indireta com ele, estabelecendo assim uma estrutura em torno deste componente. Ele está em todos os materiais fontes. Entendemos, que isso demonstra a sua centralidade. Destacamos a relação direta que o CL possui com o Proprietário do Currículo - que abordaremos a seguir - e com o Agente de Software. Contudo, não possui relação direta com o outro componente humano do sistema de informação SCL, o Staff. Com o ambiente, esse componente possui relação com a Base de Dados, com o Público Consultante, com as Instituições de Ciência, Tecnologia \& Inovação (CT\&I) e com as Agências de Fomento.

O Currículo Lattes tem como propriedade comum o fato de ser um documento em que o Proprietário do Currículo realiza atualizações da sua produção e participação em atividades CT\& I. Assim, o componente Currículo Lattes possui relação com o Proprietário do Currículo,

Perspectivas em Gestão \& Conhecimento, João Pessoa, v. 10, n. 1, p. 107-130, jan./abr. 2020. 
tendo com este um vínculo de propriedade - aqui, significando pertencimento, posse, com efeitos jurídicos de propriedade. Esse vínculo materializa-se no aceite do termo de uso que é apresentado pelo software quando a pessoa cria o currículo e quando o atualiza. Além disso, possui uma relação com o Agente de Software, sendo este um vínculo tecnológico, ou seja, infraestrutural em termos de softwares. Assim concluímos a identificação da endoestrutura que envolve diretamente o componente Currículo Lattes.

Já na exoestrutura, o Currículo tem relação com a Instituição de CT\&I, em um vínculo informacional e de interesse, ou seja, um fluxo de informação é estabelecido entre eles, por isso vínculo informacional. O vínculo de interesse emerge a partir da necessidade de resolver processos burocráticos, como processos seletivos. Possui também relação com o Público Consultante, formando um vínculo de interesse no conteúdo informacional e de conhecimento gerado pelo sistema. Por fim, o Currículo Lattes tem relação com a Base de Dados e com este possui vínculo de links e informacional.

O componente Proprietário do Currículo é uma pessoa que cria um currículo pessoal no site da PL. Todos têm como propriedade comum o fato de serem proprietários do currículo, sendo uns mais ativos que outros, ou seja, atualizam com frequência ou não o CL. Além disso, esse proprietário do currículo possui um vínculo contratual - jurídico - com o CNPq. Esse vínculo é estabelecido pelo usuário ao concordar com os Termos de Uso. Esse componente também foi encontrado em todos os materiais (apêndices $A, B, C$ e D). Portanto, ele possui relação direta com o Currículo Lattes e relação eventual, mas também direta com o Staff - que será abordado a seguir - quando há necessidade de algum serviço concernente ao funcionamento ou uso do Currículo Lattes. Outro aspecto é o fato de o proprietário possuir, por vezes, vínculo com alguma Instituição de CT\&I. Sendo assim, pertence a algum Campo Científico (elemento de entorno, que veremos adiante), ou seja, faz pesquisa científica em determinada área. Por fim, destacamos o fato de o Proprietário do Currículo possuir, muitas vezes, vínculo com as Agências de Fomento sob a forma de bolsas de pesquisa na pósgraduação, bolsa produtividade para professores ou de iniciação científica para graduandos.

O componente Proprietário do Currículo possui, além do vínculo de propriedade com o Currículo Lattes, como explicamos acima, também tem um vínculo de serviço com o componente Staff, como descrito anteriormente. Esses são seus vínculos na endoestrutura. Quanto à exoestrutura, o componente Proprietário do Currículo possui relação com Campo Científico, em um vínculo cultural e de afiliação, ou seja, o ato de atuar, participar e produzir conhecimento em determinada área científica que faz emergir esses tipos de vínculos. Por outro lado, também possui relação com a Agência de Fomento por meio de vínculos cultural, jurídico e econômico (pelo conhecimento produzido, pelo contrato com o CNPq e pela riqueza produzida pelo conhecimento).

O Staff é o outro elemento humano do sistema. Ele tem como tarefa manter e administrar a PL e, por consequência, o Currículo Lattes (KERN, 2011). Após análise de todos os materiais, identificamos como propriedade comum o fato de o componente realizar os reparos e atualizações no artefato (software). Ele também é funcionário do Mantenedor (CNPq) e possui com este um vínculo de natureza trabalhista ou de servidor público. Dentro do sistema ele possui relação de natureza técnica com o Agente de Software, ou seja, ele realiza manutenção, ele atua sobre esse componente.

Apesar disso, como dito acima, seu vínculo com o Proprietário do Currículo é eventual e, em regra, com fluxo de informação no sentido do proprietário para o Staff. Uma evidência disso encontramos na página inicial do site da PL. Lá há um exemplo de vínculo referente ao componente Proprietário do Currículo: uma central de atendimento que pode ser contatada por telefone. Por fim, esse componente, foi encontrado apenas nos artigos utilizados como ponto de partida, ou seja, em Kern $(2010,2011)$.

Perspectivas em Gestão \& Conhecimento, João Pessoa, v. 10, n. 1, p. 107-130, jan./abr. 2020. 
O componente Staff, em sua endoestrutura, possui relação com o Proprietário do Currículo. Assim, cria um vínculo de prestação de serviço, ou seja, quando acionado busca resolver determinado problema. Por outro lado, na relação com o componente Agente de Software, ele produz um vínculo técnico, como explicamos. Quanto à exoestrutura, o componente Staff possui vínculo de emprego, portanto, um vínculo trabalhista com o Mantenedor (CNPq). Quanto às relações exoestrutuais, o Staff possui relação com o Desenvolvedor Externo, ou seja, um vínculo de natureza colaborativa, atuando em parceria com este item de entorno. Além disso, possui vínculo com a Infraestrutura TIC, ou seja, um vínculo tecnológico (cabos de fibra óptica, satélites, hardwares). Por fim, o componente Staff possui uma relação com a Base de Dados, formando um vínculo informacional, ou seja, troca informação com a base de dados do SCL.

Uma vez descritos os componentes do sistema, passamos para a descrição dos elementos do entorno. Após realizar o mesmo procedimento aplicado aos componentes do sistema, chegamos a uma lista final de elementos do entorno. A lista completa é composta por 70 descritores, conforme a lista completa em apêndice em Günther (2019). A nivelação de modelagem realizado em acordo com a abordagem sistemista resultou na exclusão de alguns elementos do entorno identificados na totalidade de descritores. Isso foi necessário por pertencerem a um macronível sistêmico e não cumprirem um papel de incidência direta no sistema, como por exemplo: OCDE, OMPI, etc. Abaixo, apresentamos a lista final gerada pelo movimento de síntese e posteriormente a descrição dos seguintes elementos: (1) Mantenedor (CNPq); (2) Agências de fomento; (3) Bases de dados; (4) Instituições de CT\&l; (5) Desenvolvedor externo; (6) Público consultante; (7) Campo científico; (8) Infraestrutura TIC.

O Mantenedor (CNPq) é o propositor, bem como o principal fomentador e gestor do sistema de informação. A propriedade comum encontrada nos descritores é o ato de ofertar recursos para criar e manter currículos, os artefatos centrais do sistema de informação, em torno do qual colaboram os agentes humanos e tecnológicos. O CNPq possui relação direta com o Staff e com o Proprietário do Currículo. Este elemento de entorno foi criado em 15 de janeiro de 1951 pela Lei $n^{\circ}$ 1.310, que sofreu alterações em 08 de dezembro de 1964 pela Lei $\mathrm{n}^{\circ} 4.533$.

Segundo essa lei, o CNPq tem por finalidade promover e estimular o desenvolvimento da investigação científica e tecnológica em qualquer domínio do conhecimento. Ele está direta e imediatamente subordinado à Presidência da República. Além disso, é pessoa de direito "público, com autonomia técnico-científica, administrativa e financeira" (BRASIL, 1964). A lei expõe também que o CNPq "entrará em entendimento direto com as autoridades federais, estaduais e municipais, bem como entidades públicas e privadas, para obter apoio e cooperação" (BRASIL, 1964), ou seja, há diretriz jurídica quanto ao papel social que deve cumprir este mantenedor.

Por fim, a lei informa que o CNPq será representado pelo "seu Presidente em juízo e fora dele, ativa e passivamente" (BRASIL, 1964), bem como terá a Academia Brasileira de Ciências como órgão consultivo. É oportuno dizer que os componentes do sistema, bem como o seu entorno, têm incidência relevante sobre as ações do Mantenedor (CNPq). Uma evidência disso é o Plano de Modernização da PL, que é a uma resposta às demandas apresentadas pelos componentes do sistema e de seu entorno.

$O$ elemento do entorno Agência de Fomento congrega agências governamentais e não-governamentais como a CAPES, FAPESP, FINEP, FAPESC, agências internacionais como a Comissão Fullbrigth, OPAS, bem como fomentadores privados, como o Instituto Serrapilheira. São agências como essas que subsidiam, de alguma maneira, empresas, instituições e pessoas para que desenvolvam CT\&I. Esse subsídio pode vir em forma de recursos financeiros, recursos informacionais ou infraestrutura.

Perspectivas em Gestão \& Conhecimento, João Pessoa, v. 10, n. 1, p. 107-130, jan./abr. 2020. 
As relações desse item do ambiente com os componentes se dão com o Proprietário do Currículo por meio de vínculo cultural, jurídico e econômico. Também identificamos um vínculo informacional e de interesse com o componente Currículo Lattes. Por exemplo, o Proprietário do Currículo envia um projeto e, caso seja aprovado, a Agência de Fomento dará o aporte. Por fim, a propriedade em comum utilizada para realizar a síntese e definir o papel foi o fato de essas agências fomentarem o desenvolvimento de CT\&I.

$O$ item do ambiente Base de Dados corresponde a todas aquelas fontes de informação que se encontram nos links do componente Currículo Lattes. Segundo Kern (2010, p. 12), "são outros repositórios e iniciativas que trocam dados e links" com o Currículo Lattes. Há alguns exemplos de bases de dado em que encontramos links explícitos, isto é, que fazem referências ao Currículo Lattes. Como exemplo, citamos o SGBD, a Plataforma Sucupira, a Plataforma Carlos Chagas, a Scielo, os repositórios institucionais e as bibliotecas digitais. Esses elementos foram encontrados em todos os materiais.

A propriedade em comum é o fato de cumprirem um papel de Base de Dados. Este elemento de entorno possui relação com os componentes do sistema Agente de Software por meio de um vínculo informacional, e com o Currículo Lattespor meio de um vínculo de link software/informacional. Concluindo, neste último caso, dentro do Currículo Lattes, há links que reportam a Base de Dados e vice-versa.

O item do ambiente nominado de Instituição de CT\&I é, em sua maior parte, composto por universidades, institutos de pesquisa, dentre outros. Nos dados coletados, encontramos alguns exemplos: Redes de colaboração técnico-científica; gestores de C\&T, INPI, IBGE, INT; Empresas públicas, Petrobras, EMBRAPA, EMBRAER; INTC; Instituto INSEAD, etc. Essas instituições utilizam informações obtidas junto ao componente Currículos Lattes em seus processos seletivos e no direcionamento das bolsas recebidas das Agências de Fomento, ou seja, em processos burocráticos. Em síntese, esse é o elemento do entorno que organiza, dá forma ao processo de produção de conhecimento. Isso valida o avanço das carreiras científicas e produz conhecimento científico e tecnológico por meio de processos inerentes a comunidade científica.

O elemento do entorno Desenvolvedor Externo são aquelas empresas, institutos e grupos, contratados ou parceiros do Mantenedor para criar e aperfeiçoar (propriedade em comum). O Agente de Software, por sua vez, deve melhorar o artefato tendo em mente o seu papel dentro desse sistema de informação. Porém este vínculo ocorre entre elementos externos e foge do nosso escopo desenvolver essa parte da estrutura. Contudo, possui relação com o Agente de Software de forma técnica, ou seja, opera com técnicas de computação sobre ele. Essa relação é de interesse por ser de um elemento do entorno para um componente do sistema. Por fim, o único exemplo que encontramos nos materiais foi o Grupo Stela/UFSC.

O elemento Público Consultante é formado por todas as pessoas que buscam informações no componente Currículo Lattes sobre o Proprietário do Currículo. Esse elemento possui vínculo com o Currículo Lattes, constituindo uma relação que chamamos ser de interesse. Alguns exemplos são pessoas que fazem pesquisas e estão vinculadas ao Sistema $S$, empresas, conselhos e associações profissionais como CAU, CREA, OAB etc. ou são empresários, jornalistas, estudantes, pesquisadores individuais e outros.

O item do ambiente Campo Científico é o sistema de campos factuais de investigação científica (BUNGE, 2005). Por vezes, durante a coleta ele surge como "área do conhecimento", como no site da PL e em alguns artigos. Contudo, optamos pela concepção bungeana, que define esse elemento como uma coleção variável, representada pelas seguintes propriedades: a) comunidade científica; b) sociedade que acolhe a comunidade científica; c) domínio ou universo de discurso; d) que possua uma perspectiva geral ou um plano de fundo filosófico; e) que possua um plano de fundo formal (coleção de teorias lógicas e matemáticas atualizadas);

Perspectivas em Gestão \& Conhecimento, João Pessoa, v. 10, n. 1, p. 107-130, jan./abr. 2020. 
f) um plano de fundo específico; g) uma problemática; h) um fundo de conhecimentos; i) objetivos e j) metódica (em primeiro lugar, o método científico geral).

Os processos de produção de conhecimento se dão em campos científicos. Esse elemento, apesar de parecer um tanto abstrato, está presente em praticamente todos os materiais, bem como nos macrossistemas SNI e SNPG (contexto mais amplo do SCL). Concluindo, esse item possui relação com o Proprietário do Currículo, pois mantem com este um vínculo de afiliação.

O item do ambiente Infraestrutura TIC foi caracterizado nos termos propostos por Castells (1999, p. 89):

\begin{abstract}
Em fim fins da década de 1990, o poder de comunicação da Internet, juntamente com os novos progressos de telecomunicações e computação provocaram mais uma grande mudança tecnológica, dos microcomputadores e dos mainframes descentralizados e autônomos à computação universal por meio da interconexão de dispositivos de processamentos de dados, existentes em diversos formatos. Nesse novo sistema tecnológico o poder de computação é distribuído numa rede montada ao redor de servidores web que usam os mesmos protocolos da Internet, e equipados com capacidade de acesso aos servidores em megacomputadores, em geral diferenciados entre servidores de bases de dados e servidores de aplicativos.
\end{abstract}

Além disso, segundo The Global Information Technology Report 2016 - Innovation and Digital Economy (BALLER; DUTTA; LANVIN, 2016), do Fórum Econômico Mundial, a infraestrutura é um dos pilares para a quarta revolução industrial. Segundo esse documento, são quatro os indicadores de infraestrutura TIC de um país: cobertura de rede móvel, banda larga de internet internacional, servidores seguros de internet e produção de eletricidade. A infraestrutura "é um item do ambiente pouco determinante para a emergência de propriedades, mas do qual o sistema depende grandemente" (KERN, 2010, p. 13). Assim, esse elemento do entorno possui relação com o componente do sistema Agente de Software, tendo com este um vínculo tecnológico. Isso significa infraestrutura como suporte material. A propriedade comum é possuir os quatro indicadores de infraestrutura TIC apresentados acima.

Outro aspecto relevante durante a coleta de dados foi identificar as ligações do sistema evidentes nas seções do Currículo Lattes. Tratam-se daqueles espaços em que o dono do currículo faz as atualizações da sua produção científica tecnológica, como por exemplo, o contrato entre Mantenedor (CNPq) e Proprietário do Currículo, links para Base de Dados, etc. O trabalho de Silva et al. (2009), ao estudar melhorias para a PL, corrobora o entendimento de que essas seções seriam locais que demonstram que existem vínculos(links).

\title{
5 DISCUSSÃO
}

Para que serve um modelo de sistema? Qualquer que seja a investigação ou problema prático que se queira abordar requer saber qual é o sistema em questão. Sistemas muito complexos, como é o caso do $\mathrm{SCL}$ e da $\mathrm{PL}$, raramente são vistos de forma consensual. Kern (2011, p. 2701) relata que a visão do CNPq sobre a PL era, há cerca de uma década, de uma "base de dados de currículos, instituições e grupos de pesquisa das áreas de Ciência e Tecnologia". A mesma agência encarava a PL, há quase duas décadas, como "a integração de seus [CNPq] sistemas de informação gerenciais, instrumento fundamental não somente para as atividades de financiamento, mas também no tratamento e na difusão de informações necessárias para a formulação e a gestão de políticas de ciência e tecnologia" (SABBATINI, 2001). Eventuais intervenções a fazer requerem explicitar qual é o sistema em foco, pois essas

Perspectivas em Gestão \& Conhecimento, João Pessoa, v. 10, n. 1, p. 107-130, jan./abr. 2020. 
intervenções requerem trabalho de muitos envolvidos e concepções conflitantes estão fadadas a gerar resultados conturbados.

A identificação em poucos elementos no sistema de informação modelado e no seu entorno resultaram em doze papéis distintos. Estes elementos realizam o funcionamento do sistema. Esses papéis foram identificados a partir de procedimento que encontrou nos materiais inúmeros descritores que continham propriedades em comum, o que permitiu fazer um movimento de síntese. Buscamos isso, pois um modelo mais enxuto facilita a reflexão sobre o objeto e contribui para mapear, por exemplo, as relações-chave existentes no sistema e no seu entorno. Neste sentido, a principal contribuição é ofertar um modelo que possa potencializar estudos sobre a modernização da $\mathrm{PL}$, e em especial do seu currículo, tendo como pressuposto que a e-Science é um fato social que se impõe e cabe aos gestores desse sistema de informação adaptá-lo a essa nova realidade ou irão se deparar com a sua precarização.

Portanto, ajustar o nível de modelagem proposto em Kern (2010) em matriz de detalhamento das relações da PL sociotecnológico foi fundamental, pois a utilizamos como ponto de partida. $\mathrm{O}$ aspecto chave é o fato que a matriz apresentada é de relações do SCL e não da PL, como apresentado no artigo base. Essa constatação foi definidora para escolher modelar o SCL com base empírica ao invés da PL. Pois o SCL conta com modelo ad hoc, o que é um pressuposto para desenvolver um modelo com base empírica segundo postulado por Bunge (2012a, 2013).

Neste modelo demonstramos o que existe no sistema, o que permite explicar porque se trata de um sistema de informações. Definimos os componentes do sistema de informação SCL no nível dos papéis que os componentes e os elementos de entorno representam no e para o sistema. A decisão de definir os papéis a partir das propriedades de grupo foi tomada com base no postulado por Merton (1964, p. 311) em sua obra Teoria e Estrutura Social, em que ele explica o seguinte:

O problema de fazer classificações adequadas de grupo existe já faz muito tempo, desde logo, eu chamo a atenção [para o fato de que] uma larga linha de observadores sociológicos [terem feito isso] desde Aristóteles até os nossos dias. Ainda que esses números tentados difiram com respeito a outros, os melhores deles coincidem o requisito lógico fundamental de que uma classificação eficaz não deve ser mera e toscamente descritiva de "tipos" observados, senão que se derivará de combinações de valores de determinadas propriedades de grupo. (grifo nosso).

Para facilitar essa classificação, Bunge (1999) auxilia apontando a existência de, ao menos, duas classes de sistemas sociais: os naturais (ou espontâneos) e os artificiais (ou formais). Isso significa, segundo esse filósofo da ciência, que um sistema social surge espontaneamente ou por desenho. Quando o sistema é desenhado (planejado) ele tem como característica a promessa de satisfazer algumas necessidades e desejos de seus membros. Sabemos que o SCL não surgiu espontaneamente, ou seja, não é natural. Sendo assim ele foi desenhado para cumprir determinadas tarefas burocráticas, de controle social e, principalmente, para fomentar redes de colaboração científica.

Quanto ao controle social exercido dentro de sistemas sociais, Merton (1964) fez algumas ponderações sobre a identificação desses mecanismos. Postula o sociólogo que esse exercício de controle social, dos membros de determinado grupo, ocorre especialmente por aqueles que ocupam postos de autoridade. No sistema que estudamos, esse papel é desempenhado especialmente pelos elementos de entorno como o Mantenedor, a Agência de Fomento, as Instituições de CT\&I e pelo Campo Científico. Além disso, Merton (1964) enfatiza

Perspectivas em Gestão \& Conhecimento, João Pessoa, v. 10, n. 1, p. 107-130, jan./abr. 2020. 
que aqueles grupos que não tenham mecanismos adequados para impor autoridade a reduzirão e, como consequência, perderão a capacidade de exercer controle social.

Segundo ele, um grupo (sistema) não pode persistir sem um mínimo de controle social. Além disso, assumimos que o sistema de informação $\mathrm{SCL}$ possui como resultado dos seus processos a produção de informação estratégica. Para tanto, induz à coerção e à colaboração por parte da comunidade científica nacional no fornecimento de informações (KERN, 2010). Isso se confirma pela estrutura que inferimos, pois direciona a produção de CT\&l em certos parâmetros que são representados no software, como por exemplo: informar sobre publicação de artigos científicos, orientações, participação em bancas, etc. Assim, o caráter disciplinador, seja pela coerção seja pela colaboração, dá-se a partir da produção/participação e do respectivo lançamento dessas informações no $\mathrm{CL}$.

Neste sentido, destacamos alguns aspectos identificados pelo CNPq para modernização da PL para que ela esteja apta a enfrentar esse paradigma sintetizado na expressão e-Science. No I Seminário de Avaliação de Políticas de CT\&I, realizado em Brasília em dezembro de 2018, ocorreu paralelamente o evento EXPOLattes, que busca apresentar propostas de interação de outros sistemas com a base de currículos Lattes:

\begin{abstract}
A ideia da EXPOLattes nasceu do objetivo de disseminar à sociedade as soluções tecnológicas desenvolvidas ou resultantes do acesso a informações da base de Currículos Lattes do CNPq. Tais soluções apresentaram aplicações para a produção de informações estruturadas por meio de rotinas dinâmicas para subsidiar o processo de tomada de decisão, na integração com sistemas institucionais e na aplicabilidade a pesquisa e atividade científica.

As soluções identificadas são boas apostas na resolução de problemas ligados à temática e na construção de análises relacionadas ao cotidiano das mais variadas áreas do conhecimento e no mapeamento de competência em CT\&I, de modo a contribuir para que as iniciativas nacionais sejam mais competitivas e o funcionamento dos órgãos e programas governamentais de CT\&। brasileiros tenham a eficiência e eficácia necessárias no cumprimento de suas missões (EXPOLattes, 2018).
\end{abstract}

Alguns exemplos de ferramentas de exploração de dados foram apresentados na exposição: Cientum Sistema de Gestão de Currículos, e-Lattes (Extração e análise do CV Lattes), Plataforma Stela Experta, Painel Colabora e LattesDB. Por fim, cabe concluir que a PL e o SCL são vitais para o desenvolvimento científico brasileiro, em especial no desenvolvimento de redes colaborativas entre cientistas.

\title{
6 CONSIDERAÇÕES FINAIS
}

Em síntese, este estudo buscou dar conta das duas primeiras etapas da abordagem sistemista. Como vimos ao longo do trabalho elas são: 1) colocar todo fato social em seu contexto mais amplo (ou sistema) e; 2) dividir cada sistema em sua composição, ambiente e estrutura. Ao concluí-las, foi possível descrever o SCL como sistema de informação por meio de um modelo. A partir da metodologia utilizada foi possível concluir que a descrição de um modelo teórico, tendo como base um modelo ad hoc e acrescido de dados empíricos, proporciona um aprimoramento explicativo do sistema objeto deste estudo.

O acréscimo de dados empíricos ao modelo ad hoc, que partiu do individual (unitário), ou seja, de seus componentes - professores, estudantes, profissionais, etc., para a generalização de que estes são proprietários de currículos foi um passo fundamental para o processo de criação dos critérios de inclusão. Isso possibilitou passarmos à etapa de síntese,

Perspectivas em Gestão \& Conhecimento, João Pessoa, v. 10, n. 1, p. 107-130, jan./abr. 2020. 
em que definimos os papéis que os agentes cumprem no sistema. Dessa forma, no sentido de construir conhecimento científico por meio da formação de modelos, valemo-nos mais uma vez de Bunge $(2013$, p. 14) que afirma: "a formação de cada modelo começa por simplificações, mas a sucessão histórica dos modelos é um progresso por complexidade".

Neste sentido, o que fizemos nesta pesquisa foi complexificar o modelo e assim caracterizar uma contribuição científica, em especial, para os estudos desenvolvidos pelo grupo de pesquisa que utiliza a abordagem sistemista em Ciência da Informação e ao qual o autor está vinculado. Entretanto, não foram feitos avanços quanto aos mecanismos discutidos em Kern $(2010,2011)$. Contudo, com a descrição feita, é possível adentrar nesta etapa da abordagem sistemista que conjetura os mecanismos.

Esse é o caminho lógico segundo a abordagem sistemista (BUNGE, 1999, 2012a, 2012b), considerando que já estão descritos os componentes, itens do ambiente e estrutura (vínculos) do sistema. Portanto, a compreensão do sistema de informação SCL contribuirá para estudos que expliquem o crescimento da base curricular ou a qualidade dos dados produzidos, bem como, que deem conta das dinâmicas populacionais subjacentes. Sugerimos também, como pesquisas possíveis, estudos sobre o fluxo de doutores para a periferia, sobre a genealogia acadêmica, controle social da comunidade científica, etc.

Por fim, a PL passa nesse momento (20.04.2019) por um período de grande visibilidade. Os currículos dos membros do alto escalão do governo são escrutinados pela sociedade civil que busca saber a qualificação dessas pessoas para gerirem as pastas que receberam do presidente da república. Não é escopo deste trabalho estudar tais processos, mas tão somente chamar a atenção a título de encerramento do artigo: A PL e seu sistema de currículos emergem, de fato, como uma ferramenta de responsabilização ou accountability (ARATO, 2002), ou seja, de controle da sociedade civil sobre o Estado brasileiro. O impacto desse controle se fez sentir tão forte que boatos sobre o encerramento da Plataforma foram disseminados, tornando-se ruidosos o suficiente para que o CNPq, na página oficial da $\mathrm{PL}$, colocasse uma nota de esclarecimento, desmentindo a extinção (CNPq 2018).

\section{FINANCIAMENTO E DECLARAÇÃO DE CONFLITOS DE INTERESSE}

Este artigo deriva da dissertação de mestrado do primeiro autor (LMG), que foi bolsista da CAPES durante parte do mestrado, entre 07/2016 e 03/2017, sob orientação do último (VMK). GV e VMK são bolsistas de produtividade em pesquisa do CNPq. RCSP liderou a concepção, desenvolvimento e implementação da Plataforma Lattes com financiamento do CNPq, em vários projetos de 1997 a 2006. VMK trabalhou no Grupo Stela (UFSC) e no Instituto Stela, grupo desenvolvedor e seu sucessor, de 2003 a 2010.

\section{REFERÊNCIAS}

ARATO, Andrew. Representação, soberania popular e accountability. In: PERUZZOTTI, Enrique; SMULOVITZ, Catalina (org). Controlando la política. Ciudadanos y medios en las nuevas democracias. Buenos Aires, Editorial Temas, 2002.

ASSOCIACÃO NACIONAL DE PESQUISA E DESENCOLVIMENTO DAS EMPRESAS INOVADORAS (ANPEI). Mapa do Sistema Brasileiro de Inovação. Comitê Interação ICT - Empresa. Comitê de Fomento à Inovação. São Paulo, 2014. 33p.

BALANCIERI, Renato; BOVO, Alessandro Botelho; KERN, Vinícius Medina; PACHECO, Roberto Carlos dos Santos; BARCIA, Ricardo Miranda. A análise de redes de colaboração científica sob 
as novas tecnologias de informação e comunicação: um estudo na Plataforma Lattes. Ciência da Informação, Brasília, v.34, n.1, p.66-77, jan./abr. 2005.

BALLER, Silja; DUTTA, Soumitra; LANVIN, Bruno (eds.). Global information technology report 2016: Innovating in the digital economy. Geneva: World Economic Forum, 2016. Disponível em: http://www3.weforum.org/docs/GITR2016/WEF GITR Full Report.pdf. Acesso em: 10 abr. 2020.

BARRETO, Francisco César de Sá; DOMINGUES, Ivan. O PNPG 2011-2020: os desafios do país e o Sistema Nacional de Pós-Graduação. Educação em Revista, Belo Horizonte, v. 28, n. 03, p. 17-53, 2012.

BRASIL. Lei no 4.533, de 8 de dezembro de 1964. Altera a Lei no 1.310, de 15 de janeiro de 1951, que criou o Conselho Nacional de Pesquisas, e dá outras providências. Brasília, DF: Presidência da República. Disponível em: http://www.planalto.gov.br. Acesso em: 10 de out. de 2018

BRASIL. Ministério ciência tecnologia e inovação. Portal inovação, 2018. Disponível em: http://www.portalinovacao.mct.gov.br. Acesso em: 15 dez. 2018.

BUNGE, Mario. A world of systems. Dordrecht: D. Reidel, 1979. 314p. (Treatise on basic philosophy; v.4.Ontology; 2)

BUNGE, Mario. Buscar la filosofia en las ciencias sociales. Siglo XXI editores, s.a. de c.v., México. D.F, 1999.

BUNGE, Mario. Caçando a realidade: a luta pelo realismo. Tradução Gita K. Guinsburg. São Paulo: Perspectiva, 2010.

BUNGE, Mario. Diccionario de filosofia. 3. ed. Buenos Aires: Siglo XXI, 2005.

BUNGE, Mario. Emergencia y convergencia: novedad cualitativa y unidad Del conocimiento. Barcelona: Editoria Gedisa, S.A., 2012b.

BUNGE, Mario. La ciencia: su método y su filosofia. Buenos Aires: Ediciones Siglo Veinte, 1966.

BUNGE, Mario. Mechanism and explanation. Philosophy of the Social Sciences, v. 27, n. 4, p. 410-465, 1997.

BUNGE, Mario. Teoria e realidade. Tradução Gita K. Guinsburg. São Paulo: Perspectiva, 2013.

BUNGE, Mario. Tratado de filosofía. Barcelona: Editorial Gedisa S.A., 2012a. 4 v.

CASTELLS, Manoel. Sociedade em rede. 8. ed. Tradução Roneide Venancio Majer. São Paulo: Paz e Terra, 1999.

CONSELHO NACIONAL DE DESENVOLVIMENTO CIENTíFICO E TECNOLÓGICO (CNPq). Plano de modernização da Plataforma Lattes. Brasília, 2018a. Disponível em: http://cnpq.br/web/guest/noticiasviews//iournal content/56 INSTANCE a6MO/10157/67976 30. Acesso em: 24 maio 2019.

CONSELHO NACIONAL DE DESENVOLVIMENTO CIENTíFICO E TECNOLÓGICO (CNPq). Portal de Notícias. Brasília, 2018c. Disponível em: http://cnpq.br/web/guest/noticiasviews/journal content/56 INSTANCE a6MO/10157/72188 18. Acesso em: 29 abr. 2019.

Perspectivas em Gestão \& Conhecimento, João Pessoa, v. 10, n. 1, p. 107-130, jan./abr. 2020. 
CONSELHO NACIONAL DE DESENVOLVIMENTO CIENTíFICO E TECNOLÓGICO (CNPq). Sobre a Plataforma Lattes. Brasília, 2018b. Disponível em: http://lattes.cnpq.br/. Acesso em 15 jul. 2018.

CRESWELL, John W. Research design: Qualitative, quantitative, and mixed methods approaches, 3rd ed. Thousand Oaks-CA: Sage, 2008. 296 p.

CURRENT RESEARCH INFORMATION SYSTEMS (EuroCRIS). Disponível em: https://www.eurocris.org. Acesso em 22 maio 2019

GÜNTHER, Leonardo Lima. Análise do sistema de currículo lattes segundo o modelo CESM: rumo a um sistema de informação para e-science. 2019. 163 f. Dissertação (Mestrado em Ciência da Informação) - Universidade Federal de Santa Catarina, Florianópolis, 2019. Disponível em: https://repositorio.ufsc.br/handle/123456789/204535. Acesso em: $10 \mathrm{abr}$. 2020.

HEY, Tony. TREFETHEN, Anne. The data deluge: E-science perspectives. To be published in: Grid computing - Making the global infrastructure a reality, Wiley, January 2003

KERN, Vinícius Medina; SILVA, Luciana Mara; GARCIA, Paula Balbis; ESTÁCIO, Letícia Silvana dos Santos; ANDRADE, Wemylinn Giovana Florencio; DENISCZWICZ, Marta; GÜNTHER, Leonardo Lima; FORMOSO, Robson Garcia. A redução ao sistema como operação epistêmica na pesquisa descritiva e explicativa em ciência da informação. In: ENCONTRO NACIONAL DE PESQUISA EM CIÊNCIA DA INFORMAÇÃO, 17., 2016, Salvador-BA. Anais [...] Salvador-BA: UFBA e ANCIB, 2016. p. 301-321.

KERN, Vinícius Medina. Inovações na revisão por pares: o papel do software. Tendências da Pesquisa Brasileira em Ciência da Informação, v. 10, p. 1-17, 2017.

KERN, Vinícius Medina. O sistemismo de Bunge: fundamentos, abordagem metodológica e aplicação a sistemas de informação. In: ENCONTRO NACIONAL DE PESQUISA EM CIÊNCIA DA INFORMAÇÃO, 12., 2011, Brasília. Anais... Brasília: Thesaurus, 2011. p. 2693-2709.

KERN, Vinícius Medina. Plataformas e-gov como sistemas sociotecnológicos. In: ROVER, A. J.; GALINDO, F. (org.). 0 governo eletrônico e suas múltiplas facetas. v. 10. Zaragoza: Prensas Universitarias de Zaragoza, 2010. p. 39-67. (Série LEFIS).

LANE, Julia. Let's make science metrics more scientific. Nature, v. 464, n. 7288 , p. 488-489, 2010.

LAUDON, Kenneth C.; LAUDON, Jane Price. Sistemas de informação. 4. ed. Rio de Janeiro: LTC, 1999.

MERTON, Robert K. Teoria y estructuras sociales. Tradução Florentino M. Torner. México: Fondo de Cultura Económica, 1964.

MOTOYAMA, Shozo (org.). 50 anos do CNPq contados pelos seus presidentes. São Paulo: FAPESP, 2002.

PACHECO, Roberto Carlos dos Santos; KERN, Vinícius Medina; STEIL, Andrea Valéria. Aplicações de arquitetura conceitual em plataformas e-gov: da gestão da informação pública à construção da sociedade do conhecimento. Ponto de Acesso, Salvador, v.1, p. 71-87, jun. 2007.

PACHECO, Roberto Carlos dos Santos; KERN, Vinícius Medina. Arquitetura conceitual e resultados da integração de sistemas de informação e gestão da ciência e tecnologia.

Perspectivas em Gestão \& Conhecimento, João Pessoa, v. 10, n. 1, p. 107-130, jan./abr. 2020. 
Datagramazero, v. 4, n.2, p. 1-11, 2003. Disponível em: http://eprints.rclis.org/22797/. Acesso em: 10 abr. 2020.

PACHECO, Roberto Carlos dos Santos; KERN, Vinícius Medina. Uma ontologia comum para a integração de bases de informações e conhecimento sobre ciência e tecnologia. Ciência da Informação, Brasília, v. 30, n. 3, p. 56-63, set./dez. 2001.

PACHECO, Roberto Carlos dos Santos. Entrevista Revista Nexus. Florianópolis, 2003. Disponível em: http://blog.stela.org.br/wpcontent/uploads/2017/01/EntrevistaRevistaNEXUS2003.pdf. Acesso em: 10 abr. 2020.

REZENDE, Denis Alcides. Tecnologia da informação: integrada à inteligência empresarial. São Paulo: Atlas, 2002.

EXPOLattes - SEMINARIO DE AVALIAÇÃO DE POLÍTICAS DE C\&T, 1., Brasília, 2018. Disponível em: https://www.cgee.org.br/web/seminarioavaliacaocti/expolattes. Acesso em 23 mar. 2019.

SABBATINI, M. Lattes, o cómo gestionar la ciencia brasileña en la red. e-ciencia (Portal de ciência e tecnologia), 18 jun. 2001.

SILVA, Fabio Mascarenhas; SMIT, Johanna Wilhelmina. Organização da Informação em sistemas eletrônicos abertos de Informação Científica \& Tecnológica: análise da Plataforma Lattes. Perspectivas em Ciência da Informação, v. 14, n.1, p. 77-98, jan./abr. 2009.

Artigo recebido em 25/05/2019 e aceito para publicação em 03/04/2020 